\title{
Bridge Inductance of Closed Slot Induction Motor for Design Process
}

\author{
Fuminori Ishibashi $^{* a)}$ Member, Makoto Matsushita ${ }^{* *}$ Member \\ Sueyoshi Mizuno** Member
}

(Manuscript received May 11, 2015)

\begin{abstract}
In the design of the induction motor, the equivalent circuit is used to predict its performance. The equivalent circuit consists of the magnetizing reactance and iron loss resistance, primary and secondary resistance and primary and secondary leakage reactance.

The secondary leakage reactance of the closed slot rotor is not easy to calculate, because the closed slot rotor has a thin magnetic steel sheet bridge, through which the leakage flux passes. The inductance of the bridge changes depending on the B-H characteristics of the magnetic steel sheet.

In this paper, a new equivalent B-H characteristics method is developed to calculate the bridge inductance of the closed slot. First, the bridge inductance of the closed slot is examined with experiments, flux by FEM and magnetic energy and magnetic coenergy by FEM. Then, magnetic energy and magnetic coenergy by FEM yields the bridge inductance of the closed slot for a wide slip range characteristics. From the bridge inductance and bar currents, the magnetomotive force and flux density are calculated for the equivalent B-H characteristics.

This equivalent B-H characteristics method is able to respond to the inductance of the closed slot bridge from the unsaturated (small ampere-turn) zone of the magnetic steel sheet to the saturated (large ampere-turn) zone accurately. This yields the proper value of the bridge inductance, for which the conventional equations give a value of infinity.
\end{abstract}

Keywords: induction motor, closed slot, bridge inductance

\section{Introduction}

Induction motors are widely used in many fields, since this motor can directly start at conventional power source and can run in variable speed by inverter, having robustness and inexpensiveness ${ }^{(1)}$. Recently closed slot rotors spread in small and medium sized induction motors (abbreviated to "motor" here after). Closed slot rotors prevent leak of melted aluminum or cupper from the rotor slot in die-casting process. Also, the smooth rotor surface decreases the high frequency losses and the acoustic electromagnetic noise, with consequent improvement in efficiency.

At designing stage, the equivalent circuit of the motor is usually used to calculate designing characteristics to check specification of the motor ${ }^{(2)-(5)}$. However, the calculation of a bridge inductance of the closed slot has been problematic for a long time, because of non-linearity of the magnetic steel sheet of the closed slot rotor bridges as shown in Fig. $1^{(2)-(9)}$. As shown in Fig. 1, the leakage flux passes thin bridge of magnetic steel sheet at top of the closed slot. Due to this thin bridge of magnetic steel sheet (abbreviated to "bridge" here after), the reactance of bridge of closed slot, that is,

a) Correspondence to: Fuminori Ishibashi. E-mail: ishif@sic. shibaura-it.ac.jp

* c/o Department of Electrical Engineering, Shibaura Institute of Technology

3-7-5, Toyosu, Koto-ku, Tokyo 135-8548, Japan

** Power Systems Company, Power and Industrial Systems R\&D Center, Fuchu-Complex, Toshiba Corporation

1, Toshiba-Cho, Fuchu-city, Tokyo 183-8511, Japan inductance of the bridge changes depending on the B-H characteristics of the magnetic steel sheet.

At present, the bridge inductance is calculated using some empirical equations ${ }^{(6)-(9)}$. But these calculated results do not agree with experimental and FEM results, as described in later parts of this paper.

In this paper, method using equivalent $\mathrm{B}-\mathrm{H}$ characteristics for design is newly developed, which corresponds with iron saturation of B-H curve. This provides proper inductance of the closed slot bridge in the wide range of magnetomotive force by rotor bar currents.

First, the inductance of the bridge by magnetic energy and magnetic coenergy is compared with values by measured flux and by flux linkage of FEM. Then, the inductance of the bridge for a wide range slip is calculated by magnetic energy and magnetic coenergy in three dimensional FEM motor model. This inductance of the bridge produces equivalent B-H curve.

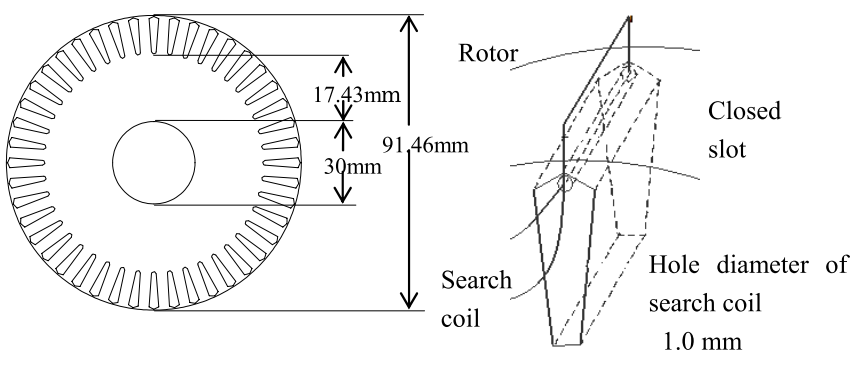

(a) Rotor plate

(b) Closed slot and search coil

Fig. 1. Closed slot rotor and flux measurement 
In designing of the motor, the bridge inductance is calculated from the equivalent B-H curve or the approximated equation. It is necessary that this defined inductance is added to that of the slot to give the total rotor slot leakage inductance. These are often termed as slot constants.

\section{Bridge Inductance by Experiments and FEM}

2.1 Bridge Inductance Equation These days, FEM produces accurate various characteristics in electrical machines and sometimes more detailed results than measured results.

The bridge inductance is calculated by magnetic energy and magnetic coenergy as follows ${ }^{(10)-(12)}$.

Magnetic energy $W_{m}$, flux linkage $\varphi$, inductance $L$, and current $i$ have following relation.

$$
W_{m}=\phi i / 2=L i^{2} / 2
$$

As bridge of closed slot is made of nonlinear material, such as magnetic steel sheet, inductance of the bridge is calculated by Eq. (2).

$$
\begin{aligned}
& W_{m}+W_{m}^{\prime}=\phi i=L i^{2} \ldots \ldots \ldots \ldots \\
& \text { where, } W_{m}^{\prime} \text { : magnetic coenergy }
\end{aligned}
$$

The inductance of the bridge $L_{\text {bridge }}$ is calculated by Eq. (3), using magnetic energy and magnetic coenergy by electromagnetic FEM.

$$
L_{\text {bridge }}=\left(\pi / 4 I_{\text {bar }}{ }^{2} T\right) \int_{0}^{T}\left(W_{m \_ \text {bridge }}(t)+W_{m \_b r i d g e}^{\prime}(t)\right) d t
$$

where $W_{m \_b r i d g e}(t)$ : bridge magnetic energy (1 slot), $W_{m \_ \text {bridge }}^{\prime}(t)$ : bridge magnetic coenergy (1slot), $T$ : slip frequency period, $t$ : time, $I_{b a r}$ : rms rotor bar current

The magnetic energy and magnetic coenergy method is equally applicable to semi-closed or open slots, which may be completely or partially filled. This method can calculate for any shape of bar placed in any shape of slot. The merit of the magnetic energy and magnetic coenergy method is independent of the bridge shape as well.

2.2 Experiment of the Closed Slot Rotor Flux through the bridge of the closed slot rotor was measured by search coil using rotor of the induction motor only ${ }^{(13)}$. Specification of the motor and the rotor is shown in Table 1 and Table 2.

Measured flux linkage by search coil in Fig. 1 yields bridge inductance by dividing the bar currents. This rotor model was analyzed by FEM, which gave flux linkage and magnetic energy of the closed slot bridge. These values provide bridge inductance, which are compared with bridge inductance by measured flux, as shown in Table 3 and Fig. 2. These results show good agreements each other. The inductances calculated from magnetic energy and magnetic coenergy provide proper values.

\section{FEM Analysis of Closed Slot Induction Motor}

The closed rotor slot induction motor in Table 1 is analyzed by three dimensional nonlinear transient electromagnetic FEM. Three dimensional FEM model, and flux density and flux line around rotor closed slots are shown in
Table 1. Specification of induction motor

\begin{tabular}{|c|c|}
\hline Items & Contents \\
\hline Pole - Output & $4-0.75 \mathrm{~kW}$ \\
\hline Voltage - Frequency & $200 \mathrm{~V}-50 \mathrm{~Hz}$ \\
\hline Rated current & $3.7 \mathrm{~A}$ \\
\hline Rated speed & $1415 \mathrm{~min}^{-1}$ \\
\hline Number of stator / rotor slot & $36 / 44$ \\
\hline Thermal class & E class \\
\hline Magnetic steel sheet & $50 \mathrm{H} 1300$ \\
\hline
\end{tabular}

Table 2. Specification of experimental rotor

\begin{tabular}{|c|c|}
\hline Items & Contents \\
\hline Number of slots & 44 \\
\hline Stack length & $37.7 \mathrm{~mm}$ \\
\hline Bar material & Aluminum \\
\hline Outer diameter & $91.46 \mathrm{~mm}$ \\
\hline Bridge depth & $0.25 \mathrm{~mm}$ \\
\hline Hole dia. for search coil & $1.0 \mathrm{~mm}$ \\
\hline
\end{tabular}

Table 3. Experimental bridge inductance

\begin{tabular}{|c|c|c|r|c|c|}
\cline { 2 - 5 } \multicolumn{1}{c|}{} & \multicolumn{3}{c|}{ FEM analysis } & \multicolumn{2}{c|}{ Experiment } \\
\hline \multirow{2}{*}{$\begin{array}{l}\text { Bar } \\
\text { current } \\
(\mathrm{A})\end{array}$} & $\begin{array}{c}\text { Inductance }(\mu \mathrm{H}) \\
\begin{array}{c}\text { By } \\
\text { flux } \\
\text { linkage }\end{array}\end{array}$ & $\begin{array}{c}\text { By } \\
\text { magnetic } \\
\text { energy \& } \\
\text { coenergy }\end{array}$ & $\begin{array}{l}\text { Flux } \\
\text { density } \\
(\mathrm{T}) \\
(\text { element })\end{array}$ & $\begin{array}{l}\text { Induct- } \\
\text { ance } \\
(\mu \mathrm{H})\end{array}$ & $\begin{array}{l}\text { Magnetic } \\
\text { flux } \\
\text { density } \\
(\mathrm{T})\end{array}$ \\
\hline 0.5 & 1.82 & 2.32 & 0.108 & 1.64 & 0.08 \\
\hline 1.0 & 2.49 & 2.64 & 0.274 & 2.24 & 0.23 \\
\hline 2.0 & 3.11 & 3.34 & 0.848 & 3.19 & 0.66 \\
\hline 4.0 & 3.28 & 3.12 & 1.652 & 3.12 & 1.28 \\
\hline 6.0 & 2.60 & 2.36 & 1.821 & 2.47 & 1.52 \\
\hline 8.0 & 2.13 & 1.90 & 1.934 & 2.02 & 1.67 \\
\hline 10.0 & 1.81 & 1.66 & 2.024 & 1.72 & 1.77 \\
\hline 12.0 & 1.58 & 1.46 & 2.103 & 1.52 & 1.87 \\
\hline 20.0 & 1.04 & 1.05 & 2.515 & 1.03 & 2.11 \\
\hline
\end{tabular}

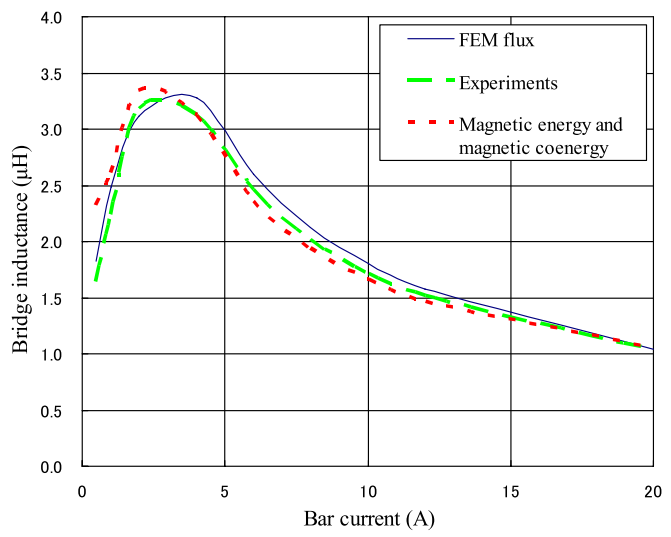

Fig. 2. Measured and calculated bridge inductances

Fig. 3 and Fig. 4 respectively. From this analysis, the bridge flux density, magnetic energy and magnetic coenergy of the bridge are provided. The bridge inductance was calculated by these magnetic energy and magnetic coenergy in Eq. (3). The bridge inductances of closed rotor slots are calculated for 


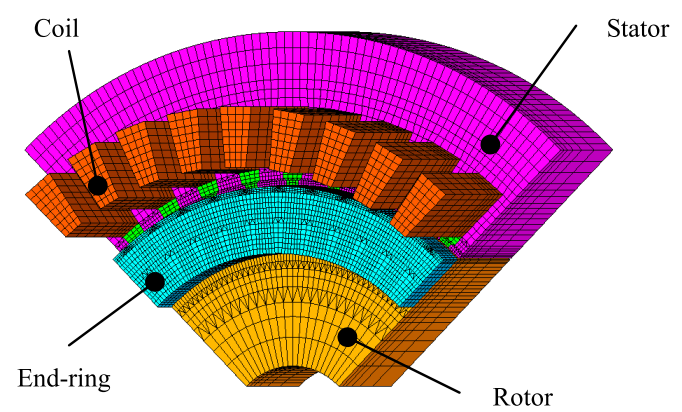

Fig. 3. Three-dimensional finite element model (1/8 region)

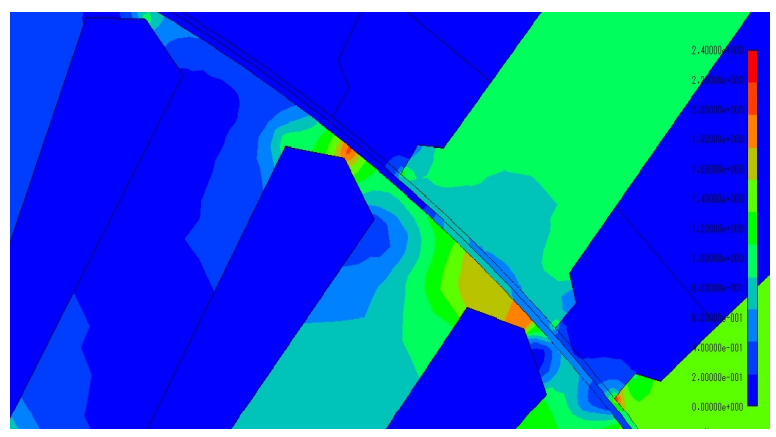

(a) Flux density distribution

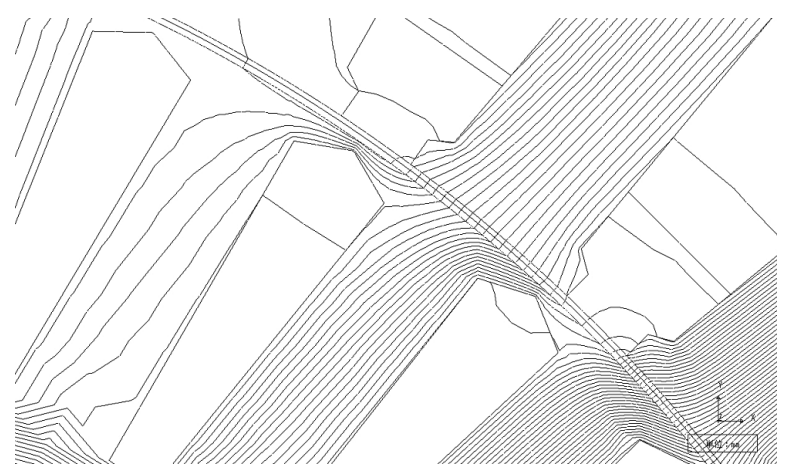

(b) Flux line

Fig. 4. Flux density distribution and flux line by FEM (at rated load)

various slip, that is, from small bar currents to large bar currents in Table 4 and Fig. 5. Bar currents were increased up to about $580 \mathrm{~A}$ at slip $100 \%$.

As mentioned in "1.Introduction", there are several conventional methods for calculation of the bridge inductance of closed slot rotor ${ }^{(6)-(9)}$. These results show the same tendency against the bar currents ${ }^{(6)-(8)}$.

In Fig. 5, the bridge inductance curve by Veinott is described $^{(7)}$. This curve drastically increases to values of infinity under bar current $4 \mathrm{~A}$. Therefore, it is difficult to use these conventional equations in designing of closed slot rotor motor. The bridge inductance curve by magnetic energy in Fig. 5 shows the maximum value at about $8 \mathrm{~A}$. Experimental results in Fig. 2 also show peak value. The inductance includes magnetic permeability of magnetic steel sheet and dimension of magnetic circuit. Therefore, bridge inductance has similar characteristics of magnetic permeability, having the maximum value.
Table 4. Bridge inductance and bridge flux density

\begin{tabular}{|c|c|c|c|}
\hline $\begin{array}{c}\text { Bar } \\
\text { currents } \\
(\mathrm{A})\end{array}$ & $\begin{array}{c}\text { Bridge } \\
\text { inductance } \\
(\mu \mathrm{H})\end{array}$ & $\begin{array}{c}\text { Flux density } \\
(\mathrm{T})\end{array}$ & $\begin{array}{c}\text { Rotor slip } \\
(\%)\end{array}$ \\
\hline 3.46 & 2.208 & 0.38 & 0.125 \\
\hline 5.24 & 3.613 & 0.50 & 0.25 \\
\hline 8.29 & 4.497 & 0.73 & 0.5 \\
\hline 16.21 & 3.551 & 0.93 & 1.0 \\
\hline 30.13 & 2.676 & 1.20 & 2.0 \\
\hline 57.80 & 1.699 & 1.40 & 4.0 \\
\hline 84.32 & 1.286 & 1.52 & 6.0 \\
\hline 132.2 & 0.913 & 1.68 & 10.0 \\
\hline 235.6 & 0.574 & 1.86 & 20.0 \\
\hline 318.8 & 0.447 & 1.96 & 30.0 \\
\hline 382.1 & 0.387 & 2.03 & 40.0 \\
\hline 435.5 & 0.351 & 2.10 & 50.0 \\
\hline 478.9 & 0.327 & 2.15 & 60.0 \\
\hline 515.4 & 0.310 & 2.19 & 70.0 \\
\hline 543.4 & 0.297 & 2.21 & 80.0 \\
\hline 559.3 & 0.293 & 2.24 & 90.0 \\
\hline 579.2 & 0.284 & 2.25 & 100.0 \\
\hline & & & \\
\hline
\end{tabular}

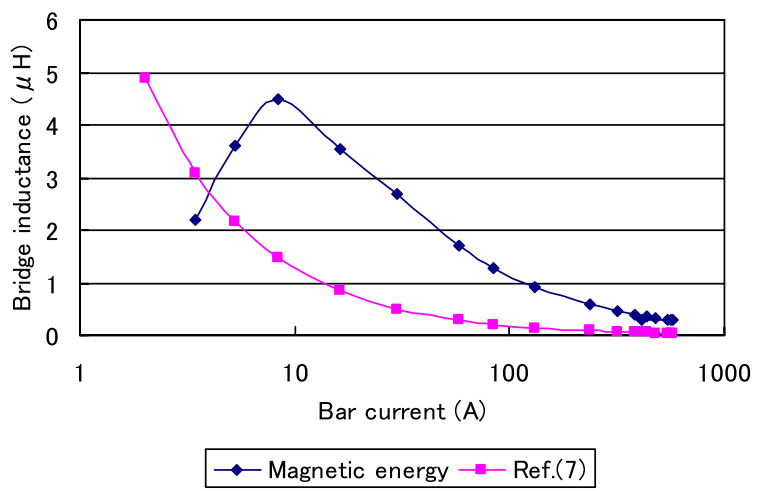

Fig. 5. Bridge inductance by magnetic energy and conventional equation in Ref. (7)

\section{Equivalent B-H Curve Method}

4.1 Calculation Process In routine design, performance of the motor is calculated by mathematics using dimensions on the drawing or in design sheet. Numerical calculation process is simplified and values for calculation are used from the drawing and the winding specification.

Equivalent B-H curve method is able to use in routine calculation of the bridge inductance of the closed slot. Equivalent B-H curve is determined from B-H curve of magnetic steel sheet by the following procedure.

Generally, B-H curve characteristics need magnetomotive force or field intensity $(\mathrm{H})$ and flux density (B). The equivalent B-H curve also needs these values. The field intensity around the slot due to the bar current is derived by Eq. (4).

$$
H_{s}=I_{b a r} /\left(l_{s u}+2 \times d_{s s}+l_{s d}\right)
$$

where, $H_{s}$ : magnetomotive force or field intensity around slot $(\mathrm{A} / \mathrm{m}), I_{\text {bar }}$ : rms. bar current (A), $l_{\text {su }}$ : slot pitch at rotor outer diameter $(\mathrm{m}), l_{s d}$ : slot pitch 
at average yoke diameter of rotor $(\mathrm{m}), d_{s s}$ : slot depth from rotor outer diameter to average yoke diameter of rotor $(\mathrm{m})$

Flux contributing the inductance of the closed slot bridge is obtained from Eq. (5). In Eq. (5), the bridge inductance $L_{\text {bridge }}$ is calculated from magnetic energy and magnetic coenergy in Eq. (3).

$$
\phi_{b r L}=L_{\text {bridge }} \times I_{b a r}
$$

where, $\phi_{b r L}$ : flux contributing slot bridge inductance $(\mathrm{Wb})$

Flux contributing the closed slot bridge inductance consists of not only the flux passing through the bridge itself, but also the flux passing nearby the bridge, that means above and below the bridge. Therefore, flux density by this flux at only bridge thickness becomes too high such as $3 \mathrm{~T}$ and so on. Flux contributing the closed slot bridge is assumed to pass through the rotor tooth. Therefore, the tooth flux density in equivalent B-H curve is obtained from Eq. (6).

$$
B_{\text {tooth }}=\phi_{b r L} /\left(0.5 \times t w \times l_{\text {core }}\right)
$$

where, $B_{\text {tooth }}$ : tooth flux density (T), $t w$ : rotor tooth width $(\mathrm{m}), l_{\text {core }}$ : rotor stack length (m)

As bridge inductance is obtained from magnetic energy and magnetic coenergy, Eq. (5) gives flux contributing slot bridge inductance. From this flux, the flux density is obtained by Eq. (6).

The flux density by Eq. (6) and the magnetomotive force by Eq. (4) bring equivalent B-H curve for the bridge of the closed slot of the motor.

Once the equivalent B-H curve for bridge is confirmed, the bridge inductance of closed slot is calculated from obtained equivalent B-H curve. Calculated bar current at design of the motor provides magnetomotive force of the bridge by Eq. (4). The equivalent B-H curve yields flux density of the bridge against this magnetomotive force. This flux density gives flux $\phi_{b r L}$ for bridge inductance by Eq. (6). From the flux $\phi_{b r L}$ for bridge and bar current, bridge inductance is calculated by Eq. (5).

\subsection{Equivalent B-H Curve Computation From} Eqs. (4), (5), and (6) for bar currents from about $4 \mathrm{~A}$ to $580 \mathrm{~A}$, the equivalent B-H curve is obtained as in Table 5 and Fig. 6. Figure 6 also shows the B-H curve of the magnetic steel sheet $50 \mathrm{H} 1300$. Compared with the B-H curve of the magnetic steel sheet $50 \mathrm{H} 1300$, the equivalent B-H curve is lower flux density in 200 11000 A/m.

As the magnetic saturation of thin bridge of closed slot starts at small magnetomotive force region, magnetic resistance becomes large. The flux through the bridge is reduced and the flux density also decreases. Thickness of the bridge is so thin that saturation of the bridge is thought to begin in small magnetomotive force. In large magnetomotive force region, the equivalent $\mathrm{B}-\mathrm{H}$ curve gradually approaches to the B-H curve of the magnetic steel sheet $50 \mathrm{H} 1300$.

This equivalent B-H curve is also approximated by a natural logarithm function as shown in Fig. 6. This natural logarithm equation becomes as in Eq. (7).

$$
\mathrm{B}_{\text {tooth }}=0.3117 \times \operatorname{Ln}\left(\mathrm{H}_{\mathrm{s}}\right)-1.1866 \text {. }
$$

\begin{tabular}{|c|c|}
\hline $\begin{array}{c}\text { Magnetomotive } \\
\text { force }(\mathrm{AT} / \mathrm{m})\end{array}$ & $\begin{array}{l}\text { Tooth flux } \\
\text { density }(\mathrm{T}) \\
\end{array}$ \\
\hline 9.27 & 0.02 \\
\hline 18.54 & 0.05 \\
\hline 37.08 & 0.14 \\
\hline 74.17 & 0.27 \\
\hline 111.3 & 0.32 \\
\hline 148.3 & 0.35 \\
\hline 168.6 & 0.38 \\
\hline 222.5 & 0.40 \\
\hline 370.8 & 0.45 \\
\hline 558.5 & 0.82 \\
\hline 1071.2 & 1.03 \\
\hline 1562.9 & 1.14 \\
\hline 2451.8 & 1.27 \\
\hline 4368.7 & 1.41 \\
\hline 5910.6 & 1.49 \\
\hline 7084.1 & 1.55 \\
\hline 8075.3 & 1.58 \\
\hline 8880.4 & 1.64 \\
\hline 9556.9 & 1.67 \\
\hline 10076.1 & 1.69 \\
\hline 10369.8 & 1.71 \\
\hline 10739.6 & 1.72 \\
\hline
\end{tabular}

Table 5. Equivalent B-H curve

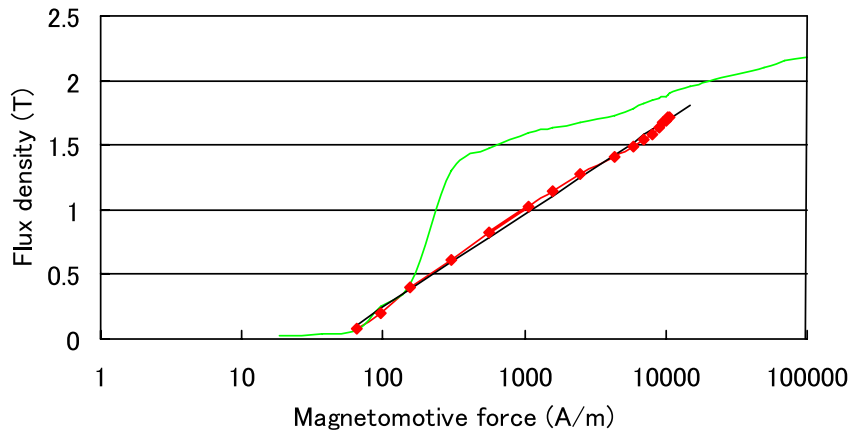

$\rightarrow$ Equivalent B-H $-50 \mathrm{H} 1300-$ Approximate curve

Fig. 6. Equivalent B-H curve, B-H curve of $50 \mathrm{H} 1300$ and approximate curve

Since all original point constitutes almost a straight line in single logarithmic chart, this approximated equation holds to a fairly good approximation. Probably, constituting of the straight line may mean that procedure of the equivalent B-H curve is properly transacted.

4.3 Different Magnetic Steel Sheets The magnetic steel sheets of the motor is 50H1300, which have not good B$\mathrm{H}$ characteristics. Bridge inductance was calculated by magnetic energy and magnetic coenergy for magnetic steel sheet $35 \mathrm{H} 210$. Compared with magnetic steel sheet $50 \mathrm{H} 1300$, this magnetic steel sheet has good B-H characteristics, such as higher flux density at lower magnetomotive forces. In this region, the bridge inductances of magnetic steel sheet $35 \mathrm{H} 210$ are calculated at $4 \mathrm{~A}$ and $10 \mathrm{~A}$ of bar current in experimental model. FEM analysis provides bridge flux density as well as bridge inductance, as shown in Table 6. In Table 6, ratio of magnetic steel sheet, $50 \mathrm{H} 1300$ to $35 \mathrm{H} 210$ in flux density 
Bridge Inductance of Closed Slot IM Design (Fuminori Ishibashi et al.)

Table 6. Bridge inductance for magnetic steel sheet $50 \mathrm{H} 1300$ and $35 \mathrm{H} 210$

\begin{tabular}{|l|c|c|c|c|c|c|c|c|}
\hline $\begin{array}{l}\text { Magnetic } \\
\text { steel sheet }\end{array}$ & \multicolumn{2}{|l|}{$\begin{array}{l}\text { Flux density (T) } \\
\text { (B-H curve of } \\
\text { steel) }\end{array}$} & \multicolumn{2}{l|}{$\begin{array}{l}\text { Bridge flux } \\
\text { density (T) } \\
\text { (FEM analysis } \\
\text { at element })\end{array}$} & \multicolumn{2}{|c|}{$\begin{array}{l}\text { Bridge inductance } \\
(\mu \mathrm{H})\end{array}$} & $\begin{array}{l}\text { Equivalent flux } \\
\text { (FEM ansity (T) } \\
\text { (Equivalent } \\
\text { B-H curve })\end{array}$ \\
\hline Bar current & $4 \mathrm{~A}$ & $10 \mathrm{~A}$ & $4 \mathrm{~A}$ & $10 \mathrm{~A}$ & $4 \mathrm{~A}$ & $10 \mathrm{~A}$ & $4 \mathrm{~A}$ & $10 \mathrm{~A}$ \\
\hline $50 \mathrm{H} 1300$ & 0.07 & 0.56 & 1.65 & 2.02 & 3.12 & 1.66 & 0.192 & 0.255 \\
\hline $35 \mathrm{H} 210$ & 1.01 & 1.27 & 1.79 & 2.02 & 3.50 & 1.70 & 0.215 & 0.261 \\
\hline $\begin{array}{l}\text { Ratio } \\
(35 \mathrm{H} / 50 \mathrm{H})\end{array}$ & 14.4 & 2.26 & 1.08 & 1.00 & 1.12 & 1.07 & 1.12 & 1.024 \\
\hline
\end{tabular}

is about $2 \sim 14$. On the other hand, ratio of the bridge inductance in $50 \mathrm{H} 1300$ to $35 \mathrm{H} 210$ is about 1.10 . This means that difference in characteristic of magnetic steel sheets may be mitigated due to the saturation of the flux density of the bridge.

When the bridge will saturated from small bar current, the difference of the bridge inductance may not be large among different magnetic steel sheet.

\section{Conclusion}

Small induction motor with aluminum or cupper cast rotor employs closed rotor slot. The calculation of the bridge inductance of the closed slot is problematic, since it varies depend on the saturation of magnetic steel sheet such as its B-H curve.

In this paper, firstly, inductance of the bridge of the closed slot is calculated by measured flux, FEM flux, and magnetic energy and magnetic coenergy.

Then, inductance of the bridge of the motor is calculated by magnetic energy and magnetic coenergy of FEM from near zero percent slip to 100 percent slip, that is, bar current from about $4 \mathrm{~A}$ to $580 \mathrm{~A}$. The bridge inductance has similar characteristics of magnetic permeability, having maximum value. These results are compared with conventional mathematical methods. Conventional mathematical equations show that the inductance of the bridge increases largely in small current region. Therefore, it is not applicable for a wide range of rotor bar currents.

For design of induction motor, the equivalent B-H curve method is newly developed. This yields proper inductance of the bridge of the closed slot of the induction motor in wide range of the bar currents, that is, the magnetomotive force.

This equivalent B-H curve method provides peak value of inductance of the bridge, which is not able to be calculated by conventional equation.

By including this curve in induction motor design procedure, its performance of the induction motor with closed slot rotor will be closer to the actual characteristics than ever. This method intends to be used in the design of the induction motor by hand calculation and in mathematical design program.

This newly developed equivalent B-H curve method will be useful in routine induction motor design.

\section{References}

( 1 ) F. Ishibashi: "Introduction to Motor Engineering", Maruzen Shuppan, p.8 (2014)

( 2 ) J. Nerg. J. Pyrhönen, and J. Partanen: "Finite Element Modeling of the Magnetizing Inductance of an Induction Motor as a Function of Torque", IEEE Trans. Magnetics, Vol.40, No.4, pp.2047-2049 (2004)

( 3 ) X.H. Wang, C. Zhu, R. Zhang, R. Tang, and H. Song-Yop: "Performance analysis of single-phase induction motor based on voltage source complex finite-element analysis", IEEE Trans. Magnetics, Vol.42, No.4, pp.587-590 (2006)

( 4 ) A. Boglietti, A. Cavagnino, and M. Lazzari: "Computational algorithms for induction motor equivalent circuit parameter determination-Part I: Resistances and leakage reactances", IEEE Trans. Ind. Electron., Vol.58, No.9, pp.3723-3733 (2011)

( 5 ) Z. Ling, L. Zhou, S. Guo, and Y. Zhang: "Equivalent Circuit Parameters Calculation of Induction Motor by Finite Element Analysis", IEEE Trans. Magnetics, Vol.50, No.2 (2014)

( 6 ) Richter: "Electrische Machinen”, VERLAG BIRKHÄUSER, pp.157-160 (1954)

( 7 ) Veinott: "Theory and design of small induction motor", McGRAW-HILL, pp.300-334 (1959)

( 8 ) М.Н. СцУнов: “ОПРЕДЕЛЕНИЕ ГЕОМЕТРИИЗАКРЫТОГО ПАЗА РОТОРА КОРОТКОЗАМКНУТОГО АСИХРОННОГО ДВИГАТЕЛЯ”, ИЗВЕСТИЯ ВЫСШИХ УЧЕБНЫХ ЗАВЕДЕНИИ, o.2, pp.150-154 (1966)

( 9 ) T.S. Birch and O.I. Butler: "Permeance of closed-slot bridges and its effect on induction-motor-current computation”, Proc. IEE, Vol.118, No.1 pp.169-172 (1971)

(10) K. Yamazaki: "An Efficient Procedure to Calculate Equivalent Circuit Parameter of Induction Motor Using 3-D Nonlinear Time-Stepping Finite-Element Method", IEEE Trans. Magnetics, Vol.38, No.2, pp.1281-1284 (2002)

(11) K. Yamazaki, A. Suzuki, M. Ohto, and T. Takakura: "Composition of Equivalent Circuit for Induction Motors Considering Stray Load Loss and Harmonic Torques Using Electromagnetic Field Analysis", IEEJ Trans. IA, Vol.130, No.8, pp.1030-1038 (2010) (in Japanese)

(12) M. Matsushita, S. Mizuno, F. Ishibashi, and S. Noda: "Secondary Circuit Parameter calculation for Induction Motor with Closed Rotor Slots and Torque characteristic calculation", IEEJ Trans. IA, Vol.133, No.6, pp.645651 (2013) (in Japanese)

(13) M. Matsushita, F. Ishibashi, T. Suzuki, and S. Noda: "Bridge Inductance of Induction Motor with Closed Rotor Slots", IEEJ Trans. IA, Vol.129, No.12, pp.1163-1168 (2009) (in Japanese)

Fuinori Ishibashi (Member) received B.E. and Ph.D. degree in electrical engineering from Kyoto University' 67 and '76 respectively. Having joined Toshiba corporation Mie ' 67 , he has been working on electromagnetic probNo Photograph lems of induction motors, while engaged in designing for certain from ' 69 to '73. He worked for Shibaura Institute of Technology in from '98. to '14. Now, he is studying brush-less permanent magnet DC motor as well as induction motor. 
Makoto Matsushita (Member) received the M.S. degree in electrical engineering from Tokyo University of Science, Chiba, Japan, in 1995. In 1995, he joined Toshiba Corporation. He is with the Power and Industrial Sys-

No Photograph for certain

reasons
Sueyoshi Mizuno (Member) graduated Komaki Technical High

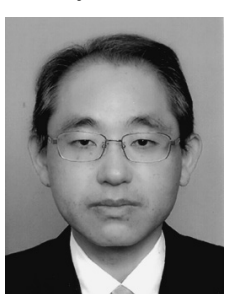
School in1982. In 1982, he joined Toshiba Corporation, Tokyo, Japan. He works in Power and Industrial Systems R\&D Center at Fuchu and has been working on acoustic noise and vibration of electrical machines. He is a member of the Japan Society of Mechanical Engineers. 